\title{
Universiteit
}

Leiden

The Netherlands

\section{Solid-state NMR study of miscibility and phase separation in blends and semi-interpenetrating networks of 13C labeled poly(styrene-co- acrylonitrile) and poly(styrene-co-maleic anhydride)}

Heinen, W.; Wenzel, C.B.; Rosenmöller, C.H.; Mulder, F.M.; Boender, G.J; Lugtenburg, J.; ... ; Groot, H.J.M. de

\section{Citation}

Heinen, W., Wenzel, C. B., Rosenmöller, C. H., Mulder, F. M., Boender, G. J., Lugtenburg, J., ... Groot, H. J. M. de. (1998). Solid-state NMR study of miscibility and phase separation in blends and semi-interpenetrating networks of 13C labeled poly(styrene-co-acrylonitrile) and poly(styrene-co-maleic anhydride). Macromolecules, 31(21), 7404-7412.

doi:10.1021/ma980436n

Version: $\quad$ Publisher's Version

License: $\quad$ Licensed under Article 25fa Copyright Act/Law (Amendment Taverne)

Downloaded from: https://hdl.handle.net/1887/3239375

Note: To cite this publication please use the final published version (if applicable). 


\title{
Solid-State NMR Study of Miscibility and Phase Separation in Blends and Semi-Interpenetrating Networks of ${ }^{13} \mathrm{C}$-L abeled Poly(styrene-co-acrylonitrile) and Poly(styrene-co-maleic anhydride)
}

\section{Wouter Heinen, ‘’ Cornelia B. Wenzel, Carola H. Rosenmoller, Fokko M. Mulder, Gert J an Boender, J ohan Lugtenburg, and Huub J . M. de Groot*}

Leiden Institute of Chemistry, Gorlaeus Laboratories, P.O. Box 9502,

2300 RA Leiden, The Netherlands

\section{Martin van Duin}

DSM Research, P.O. Box 18, 6160 MD Geeen, The Netherlands

\section{Bert Klumperman}

Eindhoven University of Technology, Laboratory of Polymer Chemistry, P.O. Box 513, 5600 MB Eindhoven, The Netherlands

Received March 19, 1998; Revised Manuscript Received J uly 21, 1998

\begin{abstract}
Site-directed isotopic enrichment and solid-state ${ }^{13} \mathrm{C}$ spin-diffusion NMR techniques were employed to characterize miscibility at the molecular level and phase separation in blends of amorphous polymers. Using 2D proton-driven spin-diffusion techniques on a mixture of ${ }^{13} \mathrm{C}$-labeled poly(styreneco-maleic anhydride), $\left[{ }^{13} \mathrm{CH}_{2},{ }^{13} \mathrm{CO}\right] \mathrm{SMA}$ (27 wt \% MA, $\mathrm{M}_{\mathrm{w}} \sim 4 \times 10^{4} \mathrm{~g} \mathrm{~mol}^{-1}$ ), and poly(styrene-coacrylonitrile), $\left.{ }^{13} \mathrm{CN}\right] \mathrm{SAN}$ (27 wt \% ACN, $\mathrm{M}_{\mathrm{w}}=1.3 \times 10^{5} \mathrm{~g} \mathrm{~mol}^{-1}$ ), it is demonstrated that SMA and SAN are miscible on the molecular level. However, a specific orientation of the nitrile moieties in SAN with respect to the carbonyl groups in SMA is unlikely. This suggests that the miscibility of SAN and SMA copolymers is associated mainly with a decrease of intramolecular repulsion upon mixing, as opposed to a specific exothermic binary interaction. In addition, spin-diffusion experiments show that upon selective cross-linking of the SMA phase semi-interpenetrating networks are formed. Increasing the degree of cross-linking results in increasing degrees of phase separation.
\end{abstract}

\section{Introduction}

Polymer Miscibility. Miscibility in mixtures of homopolymers is uncommon, but the number of fully miscible copolymers is quite large. ${ }^{1}$ For instance, high molar mass poly(styrene-co-maleic anhydride) (SMA) and poly(styrene-co-acrylonitrile) SAN are fully miscible, as demonstrated by differential scanning calorimetry (DSC) and dynamic mechanical analysis, when the amount of MA in SMA, in weight percent, is approximately equal to the amount of AN in SAN, in weight percent. ${ }^{2-5}$

Miscibility of polymers at the molecular level requires a free energy gain upon mixing, $\Delta \mathrm{G}_{\text {mix }}<0$. According to the Flory-Huggins ( $\mathrm{FH}$ ) theory, the thermodynamics of mixing depends critically on the interpolymer interactions

$$
\Delta \mathrm{G}_{\text {mix }} / \mathrm{RTV}=\sum_{\mathrm{i}, \mathrm{j}}\left(\varphi_{\mathrm{i}} \ln \varphi_{\mathrm{i}}\right) N_{\mathrm{i}}+\left(\varphi_{\mathrm{j}} \ln \varphi_{\mathrm{j}}\right) N_{\mathrm{j}}+\underset{\chi_{\mathrm{ij}} \varphi_{\mathrm{i}} \varphi_{\mathrm{j}}}{ }
$$

Here $V$ is the total volume of the system, while $V_{i}$, and $V_{\mathrm{j}}$, and $\varphi_{\mathrm{i}}$ and $\varphi_{\mathrm{j}}$ are the molar volumes and volume fractions of components $i$ and $j$, respectively. Fol lowing the standard conventions, the summation on the righthand side of this equation represents the combinatorial

* Corresponding author.

t Present address: DSM Research, P.O. Box 18, 6160 MD Geleen, The Netherlands. entropy $\Delta S_{\text {mix }} \chi_{i j} \varphi_{i} \varphi_{j}$ represents the enthal py of mixing, $\Delta \mathrm{H}_{\text {mix }}$, and the $\mathrm{FH}$ interaction parameter $\chi_{\mathrm{ij}}$ is given by

$$
\chi_{i j}=z \Delta w_{i j} r_{i} / k_{B} T V_{i}
$$

with $z$ the lattice coordination number, $\Delta w_{i j}$ the energy change due to formation of $\mathrm{i}-\mathrm{j}$ interaction pairs, $r_{i}$ the site fraction of component $i \quad\left(r_{i}\left(V_{i} N\right)\right.$, and $k_{B}$ the Boltzmann constant. For blends of polymers with a high molecular weight, the combinatorial entropy term is very small compared to the enthalpy term. This leaves the free energy of mixing as given in eq 1 proportional to the sign of $\chi_{i j}$. When $\chi_{i j}<0, \Delta G_{\text {mix }}<0$, and the components are miscible from a thermodynamic point of view.

In a general approach to describethe thermodynamics of mixing of copolymers, intramolecular interactions are taken into account. The interaction parameter $\chi_{\mathrm{ij}}$ is expanded into the linear combination of the individual interaction parameters corresponding to the various interactions between nonidentical monomeric units. F or $\mathrm{S}_{x} \mathrm{AN}_{1-x}$ and $\mathrm{S}_{y} \mathrm{MA}_{1-y}$, with the subscripts indicating the monomer fractions, the overall interaction parameter can be written as $\mathrm{s}^{6,7}$

$$
\begin{array}{r}
\chi_{\text {blend }}=\chi_{\mathrm{AN}-\mathrm{S}} \mathrm{x}^{2}+\left(\chi_{\mathrm{AN}-\mathrm{MA}}-\chi_{\mathrm{MA}-\mathrm{S}}-\chi_{\mathrm{AN}-\mathrm{S}}\right) \mathrm{xy}+ \\
\chi_{\mathrm{MA}-\mathrm{S}} \mathrm{y}^{2}
\end{array}
$$

It was deduced from miscibility data that $\chi_{\mathrm{MA}-\mathrm{S}}=$ 1.85, $\chi_{\mathrm{AN}-\mathrm{S}}=0.98$, and $\chi_{\mathrm{AN}-\mathrm{MA}}=0.04$ at $\mathrm{T}=300 \mathrm{~K}$, 
i.e., all binary interaction parameters are positive. ${ }^{8}$ Since there are no exothermic binary interactions, homogeneous blends of SMA and SAN can only be obtained by an appropriate choice of $x$ and $y$. For every blend component, the immediate presence of another (co)polymer component is thought to reduce the internal repulsion, resulting in full miscibility. However, negative values for $\chi_{\mathrm{AN}-\mathrm{MA}}$ have also been reported. $3,10,11$ This would imply that specifically the AN and MA monomeric units are subject to an attractive, exothermic, el ectrostatic interaction. In addition, molecular modeling studies have indicated that nonbonding MA-AN interactions favor a specific mutual orientation of MA and AN moieties. ${ }^{11}$ IR studies on mixtures of low-molecular weight anhydrides and nitriles suggest that such a specific interaction can exist, since addition of 1,3dicyanobutane to propionic anhydride or acetic anhydride causes a shift of the infrared $\mathrm{C}=\mathrm{O}$ bands to lower frequencies by about $2-3 \mathrm{~cm}^{-1}$ and changes in peak intensities. ${ }^{9}$ In this study we will demonstrate how solid-state NMR distance measurements can help answer the question whether the AN units in SAN and the carboxyl moieties in SMA are in close contact in SMA/SAN blends.

Cross-linking of the SMA phase in a SAN/SMA blend can be achieved using difunctional compounds such as diamines, diols, or bisoxazolines. When the crosslinking agent reacts with two anhydride moieties of two different SMA chains, a semi-interpenetrating polymer network (semi-IPN) is formed, i.e., one of the two polymer components in the blend is cross-linked and forms a continuous system with the non-cross-linked phase. ${ }^{12-14,15}$

Semi-IPNs of ${ }^{13} \mathrm{C}$-labeled SMA and SAN may be of interest to examine the molecular mechanisms behind the stabilization of the blend and to develop experimental approaches for measuring the extent of phase separation upon cross-linking.

MAS NMR. Solid-state magnetic resonance techniques are frequently used to investigate the morphology ${ }^{17-21}$ and dynamics ${ }^{21-23}$ in multicomponent polymeric materials. In spin-diffusion experiments, the transfer of polarization from one distinct site in a material to another is probed. ${ }^{24}$ Zero quantum flip-flop type transitions are the basic steps in spin diffusion. ${ }^{24,25}$ In a two-spin approximation, the transition probability, $\mathrm{P}(\mathrm{t})$, for two nuclei $\mathrm{j}$ and $\mathrm{k}$ with $\mathrm{L}$ armor frequencies $\omega_{\mathrm{j}}$ and $\omega_{\mathrm{k}}$ is given by ${ }^{25}$

$$
P(t)=1 / 2 \pi g_{0}^{j k}\left(\omega_{j}-\omega_{k}\right) \omega_{D}{ }^{2} t
$$

In this equation $\mathrm{g}_{0} \mathrm{k}\left(\omega_{\mathrm{j}}-\omega_{\mathrm{k}}\right)$ represents the zero quantum line shape and $\omega_{\mathrm{D}}$ represents the strength of the dipolar interaction between the two nuclear magnetic moments. This formula indicates that two conditions need to be fulfilled for efficient spin diffusion: there must be an interaction $\omega_{\mathrm{D}}>0$ between the nuclei involved and the transition energies should partially overlap.

A matching of the ${ }^{13} \mathrm{C}$ energy levels can be accomplished in different ways. With rotational resonance $\left(R^{2}\right)$, matching is achieved in a narrow range of the spectrum by adjusting the sample spinning speed to maximize overlap between a spinning sideband signal and the center band response of the other nucleus. ${ }^{26-29}$ This can only be effectively accomplished when the inhomogeneous broadening of the resonances is rela-
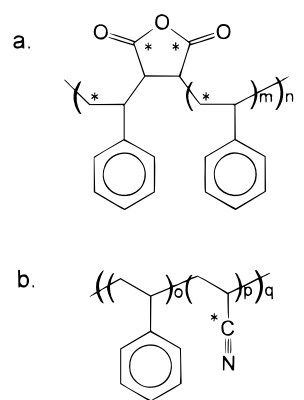

Figure 1. Structures of poly(styrene-co- $\left[{ }^{13} \mathrm{C}\right]$ acrylonitrile) and poly $\left(\left[{ }^{13} \mathrm{CH}_{2}\right]\right.$ styrene-co- $\left[{ }^{13} \mathrm{CO}\right]$ maleic anhydride).

tively small. In radio-frequency (RF)-driven dipolar recoupling (RFDR), the chemical shifts are refocused using a rotor-synchronized train of $\pi$-pulses. ${ }^{30-33} \mathrm{For}$ multicomponent systems, spin diffusion across domain boundaries can only be detected if the dipolar interactions are strong and the materials are intimately mixed, which is hard to achieve for ${ }^{13} \mathrm{C}$. In practice, ${ }^{13} \mathrm{C}$ spin diffusion only becomes significant on a time scale of 10 100 s. ${ }^{18,35}$ At longer times, spin-lattice relaxation competes with the spin diffusion and sensitivity is lost. In addition, the lifetime of the zero quantum coherence is limited, and for longer pulse trains, the refocusing becomes less efficient due to RF inhomogeneity and pulse imperfections. As a consequence, only short mixing times can be employed and hence short distances ( $\leqslant 5$ $\AA$ ) can be probed using $R^{2}$ and RFDR. Finally, in ${ }^{1} \mathrm{H}$ driven ${ }^{13} \mathrm{C}$ spin diffusion the ${ }^{13} \mathrm{C}$ lines are broadened by the dipolar coupling with the ${ }^{1} \mathrm{H}$ nuclei, yiel ding extended overlap of the NMR responses. 17,32,34-41 The longer mixing times that can be used with this technique allow probing of somewhat longer distances $(\leq 7 \AA)$.

Goal. The purpose of this study is to explore the benefits of ${ }^{13} \mathrm{C}$ labeling in conjunction with ${ }^{13} \mathrm{C}$ NMR for investigation of mixtures of amorphous polymers. Various ${ }^{13} \mathrm{C}$ spin-diffusion techniques are used to probe the nature of SMA/SAN miscibility and to evaluate the applicability of solid-state NMR techniques to follow demixing in SMA/SAN semi-IPNs. Site-directed enrichment with ${ }^{13} \mathrm{C}$ favors the spin-diffusion processes, since the probability of finding a ${ }^{13} \mathrm{C}$ pair is strongly enhanced. First, the preparation of isotopically labeled SAN and SMA copolymers containing equal weight amounts of $A N$ and $M A$, respectively, are described. These copolymers are used to prepare labeled 1:1 wt/ wt SAN/SMA blends and semi-IPNs (Figure 1). We have label ed the nitrile group in SAN and the carbonyl in SMA. In addition, the methylene unit in SMA was labeled. The three labels give rise to clearly distinguishable signals in separate regions of the ${ }^{13} \mathrm{C} N \mathrm{NMR}$ spectrum. A characteristic intramolecular carbonyl to methylene distance in each $\mathrm{S}-\mathrm{MA}-\mathrm{S}$ triad is $\sim 3 \AA$, and the analysis of the polarization transfer process between these two labels in SMA can provide an internal calibration of the spin-diffusion rate. Conversely, the measurement of intermolecular spin-diffusion rates from the SAN nitrile label to the SMA methylene and carbonyl labels can help to address the question whether the SMA/SAN blends are miscible due to a specific and predominantly strong local exothermic interaction between the nitrile and the carbonyl.

\section{Experimental Section}

Synthesis of Labeled Monomers. $\left[1,4-{ }^{13} \mathrm{C}_{2}\right] \mathrm{MA}$ was synthesized starting from $\left[1{ }^{-13} \mathrm{C}\right]$ acetic acid (Cambridge Iso- 
topes Laboratories, 99\% enriched). The acetic acid was first converted to ethyl bromo[1-13 C]acetate via the Hell-VollhardZelinskii reaction. ([1-13 C]carbethoxymethyl)triphenylphosphonium bromide was prepared by reacting the ethyl ([1${ }^{13} \mathrm{C}$ ]bromoacetate with triphenylphosphine. The Wittig salt was deprotonated and coupled oxidatively in the presence of 0.5 equiv of triphenyl phosphite-ozone adduct to yield [2,3${ }^{13} \mathrm{C}_{2}$ ]diethylfumarate. ${ }^{42}$ This was hydrolyzed by refluxing in concentrated hydrochloric acid. The resulting $\left[1,4-{ }^{13} C_{2}\right]-$ fumaric acid was isomerized and dehydrated by heating in the presence of diphosphoruspentoxide to give $\left[1,4-{ }^{13} \mathrm{C}_{2}\right] \mathrm{MA}$. The overall yield was $45 \%$ based on acetic acid. A good incorporation of isotope labels was confirmed with NMR and mass spectrometry. ${ }^{43,45} \mathrm{mp} 53{ }^{\circ} \mathrm{C} ;{ }^{1} \mathrm{H}$ NMR $(300 \mathrm{MHz}) \delta$ (ppm) 7.07 $[\mathrm{m}, \mathrm{CH}=\mathrm{CH}] ;{ }^{13} \mathrm{C}$ NMR $(75 \mathrm{MHz}) \delta(\mathrm{ppm}) 136.89[\mathrm{~m}, \mathrm{CH}=$ $\mathrm{CH}], 164.15\left[2 \times\left({ }^{13} \mathrm{C}=\mathrm{O}\right)\right]$; MS m/z $\left.100\left[32,{ }^{13} \mathrm{C}_{2} \mathrm{C}_{2} \mathrm{H}_{2} \mathrm{O}_{3}\right]^{\cdot+}\right]$, $55\left[56, \mathrm{M}-{ }^{13} \mathrm{CO}_{2}{{ }^{++}}^{+}\right], 26\left[100, \mathrm{M}-{ }^{13} \mathrm{CO}_{2}-{ }^{13} \mathrm{CO}^{++}\right]$.

$\left[1-{ }^{13} \mathrm{C}\right.$ ]acrylonitrile was synthesized starting from $30 \mathrm{~g}$ of $\mathrm{K}^{13} \mathrm{CN}$ (Cambridge Isotopes Laboratories, 99\% enriched), employing flash vacuum thermolysis as the key step. ${ }^{45,46}$ Briefly, about $6 \mathrm{~g}$ of $\left[\beta_{-13}{ }^{13} \mathrm{C}\right]$ styrene $(60 \mathrm{mmol})$ has been prepared in $43 \%$ overall yield starting from iodo[ $\left.{ }^{13} \mathrm{C}\right]$ methane. I odo $\left[{ }^{13} \mathrm{C}\right]$ methane was reacted with triphenyl phosphine to give $\left.{ }^{[13} \mathrm{C}\right]$ methyltriphenylphosphonium iodide. An emulsion of sodium hydride in mineral oil was thoroughly washed with n-pentane to remove the oil and added to dry DMSO. After the mixture was stirred in a pure nitrogen atmosphere at elevated temperature, the labeled Wittig salt was added. Subsequently, benzal dehyde was added and the mixture was stirred overnight. The reaction mixture was poured on ice and the aqueous layer was extracted thoroughly with n-pentane. The organic factions were collected and were fractionated by distillation, which yielded $6.32 \mathrm{~g}$ of $\left[\beta-{ }^{13} \mathrm{C}\right]$ styrene: ${ }^{1} \mathrm{H}$ NMR $\left(300 \mathrm{MHz} \mathrm{CDCl}_{3}, \mathrm{~J}\right.$ in $\mathrm{Hz}$ ), $\delta$ (ppm) 5.22 [ddd, $1 \mathrm{H},{ }^{1} \mathrm{~J} 13 \mathrm{C}-1 \mathrm{H}$

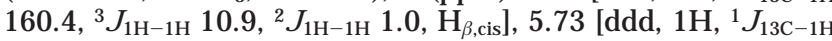
$154.4,3_{1 H-1 H} 17.6$, ${ }^{2} \mathrm{~J} 1 \mathrm{H}-1 \mathrm{H}$ 1.0, $\left.\mathrm{H}_{\beta, \text { trans }}\right], 6.70[\mathrm{dd}, 1 \mathrm{H}, 3 \mathrm{~J} 1 \mathrm{H}-1 \mathrm{H}$ 10.9, 17.7, $\left.\mathrm{H}_{\alpha}\right], 7.19-7.42\left[\mathrm{~m}, 5 \mathrm{H}\right.$, arom H]. ${ }^{13} \mathrm{C}$ NMR $(75 \mathrm{MHz})$ $\delta(\mathrm{ppm}) 113.8\left[\beta_{-13} \mathrm{CH}_{2}\right], 126.2\left[\mathrm{~d}, 3 \mathrm{~J}{ }_{13 \mathrm{C}-13 \mathrm{C}} 5.0, \mathrm{C}-2\right], 127.8$ [C-4], $128.5[\mathrm{C}-3, \mathrm{C}-5], 137.0\left[\mathrm{C}_{1}\right], 137.2\left[\mathrm{~d}, 1 \mathrm{~J}{ }_{13 \mathrm{C}-13 \mathrm{C}} 69, \alpha-\mathrm{CH}\right]$; MS (EI) $\mathrm{m} / \mathrm{z} 78\left(31 \%, \mathrm{M}-277^{\circ+}\right.$, loss of $\left.\mathrm{H}^{13} \mathrm{C} \equiv \mathrm{CH}\right), 79(20, \mathrm{M}$ $-267^{++}$, loss of $\mathrm{HC} \equiv \mathrm{CH}$, involving label scrambling in the ion source $)^{47} 104\left(44 \%, M-17^{+}\right), 105\left(100 \%, M 7^{++}\right.$either styrenyl radical cation or cyclooctatetraenyl radical cation), ${ }^{47} 106$ (11\%, $\left.\mathrm{M}+17^{+}\right) .{ }^{13} \mathrm{C}$ and ${ }^{1} \mathrm{H}$ NMR spectroscopy confirmed the incorporation of a label at the $\beta$-position of the styrene. After integrating the various olefinic responses in the ${ }^{1} \mathrm{H} N M R$ spectrum it could be determined that the incorporation is at least $98 \%$. The peak pattern in the $\mathrm{m} / \mathrm{z} 100-110$ region of the mass spectrum of $\left[\beta-{ }^{13} C\right]$ styrene is very similar to that of the mass spectrum of styrene, with the distinction that the pattern is shifted one $\mathrm{m} / \mathrm{z}$ unit (data not shown). This confirms that the ${ }^{13} \mathrm{C}$ labeling is nearly complete.

Starved-Feed Preparation of Poly $\left[\beta-{ }^{13} \mathrm{C}\right]$ (styrene-co$\left[1,4-{ }^{13} C_{2}\right]$ MA). To prepare SMA with a desired MA content and molecular weight, a starved-feed polymerization procedure was used. ${ }^{48}$ The conditions were first optimized using unlabeled monomers. In particular, the starting concentrations of the monomers and the initiator were varied. After each trial experiment, the copolymer composition and its molecular weight were determined. In a typical procedure, a mixture of $0.96 \mathrm{~g}$ of MA, $5.04 \mathrm{~g}$ of styrene, $30 \mathrm{mg}$ of AIBN, and $5 \mathrm{~mL}$ of 2-heptanone was added at a rate of $17.3 \mathrm{~mL} / \mathrm{h}$ with a dosing pump through a flexible tube to $6 \mathrm{~mL}$ of 2-heptanone that was maintained at a temperature of $130{ }^{\circ} \mathrm{C}$ in a nitrogen atmosphere while being stirred. Polymerization inside the tubing was avoided by cooling of the tube with a condenser. The reaction mixture containing the precipitated polymer was poured in a 5-fold excess of 2-propanol. After washing with 2-propanol and drying at $70{ }^{\circ} \mathrm{C}$ and at reduced pressure, $2.8 \mathrm{~g}$ of a fluffy white powder was obtained. Hence, $~ 80 \%$ of the $\mathrm{MA}$ and $\sim 40 \%$ of the styrene were converted. The molecular weight was determined from the intrinsic viscosity. ${ }^{49}$ The MA content was determined using a calibrated infrared spectroscopic method, from the ratio of the intensities of the $\mathrm{C}=\mathrm{O}$ stretch absorption at $1860 \mathrm{~cm}^{-1}$ and the $\mathrm{CH}_{2}$ bend absorption

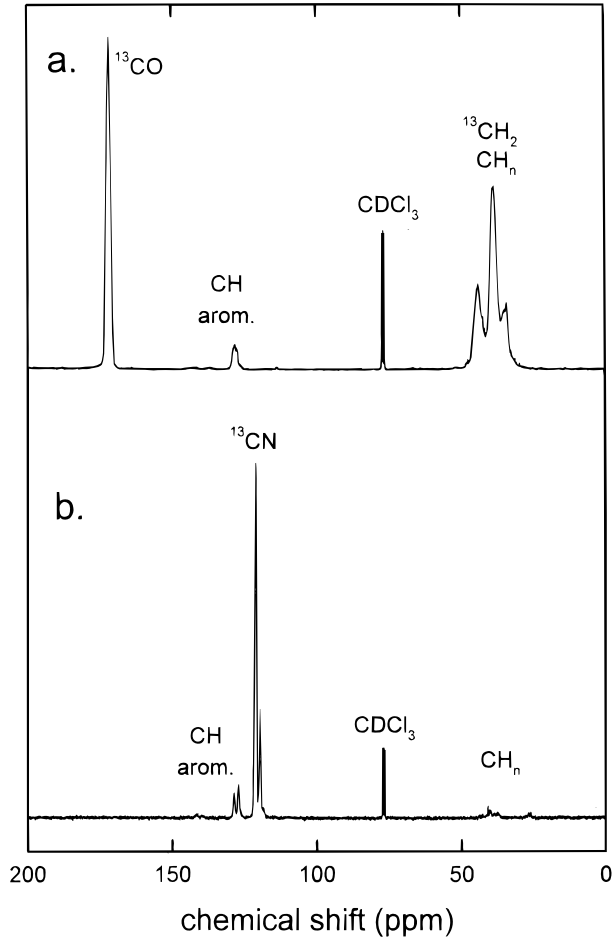

Figure 2. ${ }^{13} \mathrm{C}$ NMR spectra of (a) $\left[{ }^{13} \mathrm{CH}_{2},{ }^{13} \mathrm{CO}\right] \mathrm{SMA} 27$ and (b) $\left[{ }^{13} \mathrm{CN}\right] \mathrm{SAN} 27$ in $\mathrm{CDCl}_{3}$.

at $1494 \mathrm{~cm}^{-1}$. FT-IR spectra of SMA included in $\mathrm{KBr}$ pellets were recorded with a Perkin-EImer $1720 \mathrm{FT} / \mathrm{IR}$. Chemical composition distributions (CCDs) were determined with gradient polymer elution chromatography (GPEC), using isooctane and slightly acidified THF. Starting from pure octane the concentration of THF was gradually increased with time. The concentration of polymer in the eluent was calculated from the UV absorption due to the SMA phenyl rings at $\lambda=256$ $\mathrm{nm}$. From these GPEC measurements it was concluded that the styrene concentration is evenly distributed around a single mean value. Little or no polystyrene or SMA of (very) low MA content is formed during the starved-feed polymerization procedure.

An amount of $3.1 \mathrm{~g}$ of poly $\left(\left[\beta^{-13} \mathrm{C}\right]\right.$ styrene-co-[1,4-13 $\left.\mathrm{C}_{2}\right]$ maleic anhydride) with 27 wt $\%\left[1,4-{ }^{13} \mathrm{C}_{2}\right] \mathrm{MA}\left(\mathrm{M}_{\mathrm{w}} \sim 4 \times 10^{4} \mathrm{~g} \mathrm{~mol}^{-1}\right.$ was prepared using the optimized starved-feed procedure. The ${ }^{13} \mathrm{C}$ NMR spectrum of $\left[{ }^{13} \mathrm{CO},{ }^{13} \mathrm{CH}_{2}\right] \mathrm{SMA} 27$ in solution shows natural abundance aromatic carbon responses with $\delta=130-$ $135 \mathrm{ppm}$, and the labeled carbonyl responses with $\delta \approx 172$ ppm (Figure 2a). The complicated line shape of the ${ }^{13} \mathrm{CH}_{2}$ response has been attributed to the different monomer se quences in the SMA copolymer. ${ }^{50,51}$ The signals with $\delta=42-$ $47 \mathrm{ppm}$ have been assigned to SSS triads and are relatively strong. This indicates a high styrene content, in good agree ment with IR and DSC results. The DSC measurements were performed using a Mettler TA3000 instrument. The DSC data were collected using a heating rate of $10 \mathrm{~K} \mathrm{~min}^{-1}$ after annealing for $5 \mathrm{~min}$ at $230{ }^{\circ} \mathrm{C}$. The glass transition temperature, $\mathrm{T}_{\mathrm{g}}=163^{\circ} \mathrm{C}$, was determined from the inflection point of the DSC trace (Figure 3a). The glass temperature is close to the $\mathrm{T}_{\mathrm{g}}=162{ }^{\circ} \mathrm{C}$ reported for commercial SMA28. The relative amount of MA in the copolymer is $27.0 \mathrm{wt} \%$, from the ratio of the intensities of the ${ }^{13} \mathrm{CO}$ stretch absorption at $1807 \mathrm{~cm}^{-1}$ and the ${ }^{13} \mathrm{CH}_{2}$ bend absorption at $1493 \mathrm{~cm}^{-1}$ in the FT-IR spectrum of the material.

Synthesis of Poly(styrene-co-[1-13 C]acrylonitrile). For the preparation of poly(styrene-co-[1-13 C]acrylonitrile) with 27 wt $\%$ of $\left[{ }^{1-{ }^{13}} \mathrm{C}\right]$ acrylonitrile $\left(\left[{ }^{13} \mathrm{CN}\right] \mathrm{SAN} 27\right), 4.80 \mathrm{~g}$ of freshly distilled styrene, $2.70 \mathrm{~g}$ of $\left[1^{-13} \mathrm{C}\right]$ acrylonitrile, $1.0 \mathrm{~g}$ of a $5 \mathrm{wt}$ $\%$ solution of sodium stearate in water, $60 \mathrm{mg}$ of tertdodecylmercaptane, and $10 \mathrm{mg}$ of sodium persulfate were added to $45.0 \mathrm{~g}$ of water. The emulsion was stirred vehemently 


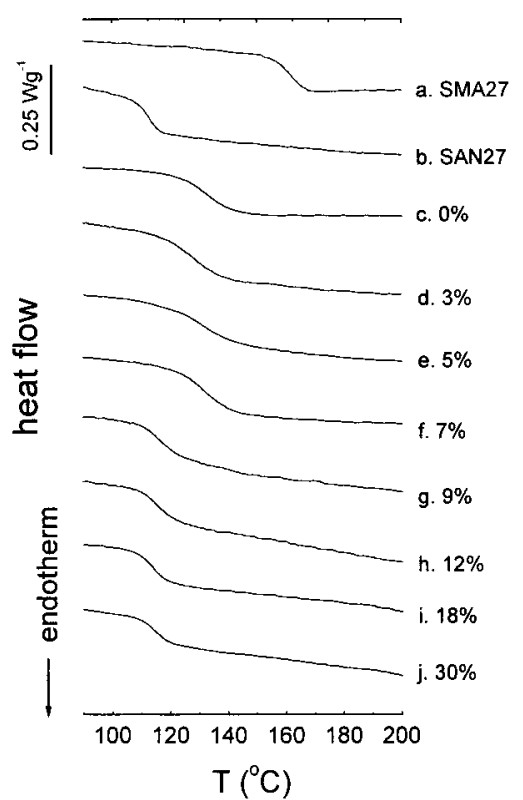

Figure 3. DSC thermograms of the $\left[{ }^{13} \mathrm{CN}\right] \mathrm{SAN} 27$ and $\left[{ }^{13} \mathrm{CH}_{2},{ }^{13} \mathrm{CO}\right] S M A 27$ copolymers $(\mathrm{a}, \mathrm{b})$, the $50 / 50(\mathrm{w} / \mathrm{w})$ blend (c), and various semi-IPNs (d-j). The semi-IPNs were prepared with 4,4'-methylenedianiline cross-linker. The percentages indicate the equival ent of dianiline functionalities relative to the amount of CO functionalities in the SMA.

and heated to $70{ }^{\circ} \mathrm{C}$ for $2 \mathrm{~h}$. Subsequently, the latex was coagulated in a 5-fold excess of methanol, which was acidified with $1 \mathrm{vol} \%$ of saturated aqueous hydrochloric acid. The product was washed thoroughly with methanol and dried for $24 \mathrm{~h}$ at $70{ }^{\circ} \mathrm{C}$ at reduced pressure, yielding $5.91 \mathrm{~g} \mathrm{(79 \% )} \mathrm{of} \mathrm{a}$ fluffy white powder. The molecular weight $\mathrm{M}_{\mathrm{w}}=1.3 \times 10^{5} \mathrm{~g}$ $\mathrm{mol}^{-1}$, was measured with gel permeation chromatography (GPC). Using elemental $\mathrm{C}, \mathrm{H}$ and $\mathrm{N}$ analysis a $27.0 \mathrm{wt} \%$. $\left[1-{ }^{13} \mathrm{C}\right]$ acrylonitrile content was found. The ${ }^{13} \mathrm{C}$ NMR spectrum of the SAN in solution shows strong signals from the nitrile labels with $\delta=119.7$ and $\delta=121.2 \mathrm{ppm}$ (Figure 2b). The glass transition temperature is $113^{\circ} \mathrm{C}$, in good agreement with the $T_{g}=112^{\circ} \mathrm{C}$ for commercial SAN28 (Figure 3b). The CCD was determined with GPEC. The initial eluent was pure n-hexane, and increasing amounts of THF were mixed in during the analysis. The GPEC trace shows a single sharp maximum at 26.9 wt \% of acrylonitrile (data not shown). A minor fraction of acrylonitrile-rich polymer was detected, which is probably due to composition drift or water-based polymerization.

Preparation of Blend and Semi-IPNs of ${ }^{13} \mathrm{C}$-Labeled SAN and SMA. To blend $\left[{ }^{13} \mathrm{CN}\right] \mathrm{SAN} 27$ and $\left[{ }^{13} \mathrm{CH}_{2},{ }^{13} \mathrm{CO}\right]$ SMA27, $200 \mathrm{mg}$ of each labeled copolymer was codissolved in $20 \mathrm{~mL}$ of acetone ( $2.5 \mathrm{wt} \%$ solution) at room temperature. After the copolymers were completely dissolved, the mixture was stirred for another $10 \mathrm{~min}$. Subsequently, the bulk of the solvent was allowed to evaporate at ambient temperatures. The blend was dried at $50{ }^{\circ} \mathrm{C}$ and at reduced pressure for at least $48 \mathrm{~h}$. Semi-IPNs were prepared in a similar procedure. The 4,4'-methylenedianiline cross-linker was first dissolved in a small fraction of the acetone and added to the SMA-SAN solution. Figure 3 shows the DSC thermograms of the labeled SMA27 and SAN27 (a, b), of the blend (c), and of the SemiIPNs prepared with different amounts of 4,4'-methylenedianiline $(d-j)$. When more than $9 \%$ cross-linker per monomeric unit in SMA is added, the semi-IPNs appear phase-separated on the scale of the DSC. Mixtures prepared with 3-7\% diamine cross-linker give rise to thermograms indicating intermediate stages of demixing.

NMR Spectroscopy. Solution ${ }^{13} \mathrm{C}$ NMR spectra were recorded with a Bruker DPX300 spectrometer using standard pulse programs. The materials were dissolved in $\mathrm{CDCl}_{3}$ and the spectra were collected at room temperature. Chemical shifts are given relative to TMS using the signal from the natural abundance ${ }^{13} \mathrm{C}$ in the solvent as an internal standard $(\delta=77.0 \mathrm{ppm})$. All solid-state ${ }^{13} \mathrm{C}$ NMR spectra were recorded of fragments of the sample films using a Bruker MSL400 spectrometer. The fragments were first annealed for $5 \mathrm{~min}$ at $230{ }^{\circ} \mathrm{C}$ in a preheated oven. Wide line ${ }^{1} \mathrm{H}$ NMR spectra were recorded with a single channel probe using a $\pi / 2$ pulse. $1 \mathrm{D}$ and $2 \mathrm{D}{ }^{13} \mathrm{C}$ variable amplitude cross polarization (VACP) MAS NMR spectra were recorded with a contact time of $2 \mathrm{~ms}$ using a double-resonance $4 \mathrm{~mm}$ MAS probe. During the VACP, the ${ }^{1} \mathrm{H}$ power was varied between $35 \%$ and $65 \%$ of the $\mathrm{CW}$ decoupling power, corresponding to a nutation frequency of $\sim 50 \mathrm{kHz}$. The VACP was optimized by adjusting the ${ }^{13} \mathrm{C}$ power for maximum signal intensity from a sample of $\left[1^{13} \mathrm{C}\right]$ glycine before every 2D experiment. The spectra were collected with sweep widths between 20 and $50 \mathrm{kHz}$ using a recycle time of $1 \mathrm{~s}$.

To examine the possibilities for using ${ }^{13} \mathrm{C}$ spin diffusion to probe the polymer blend structure, various pulse schemes were used. Figure 4 gives the schematic representations of the 1D proton driven spin diffusion (a), 2D proton driven diffusion (b), RFDR (c), and 1D rotational resonance pulse sequences (d). In the 2D experiments, the phase $\varphi_{1}$ of the ${ }^{1} \mathrm{H}-{ }^{13} \mathrm{C}$ VACP is varied in a TPPI scheme. For the RDFR experiment, an XY 8 train of rotor-synchronized $\pi$ pulses during the mixing time $\tau_{m}=8 n \tau_{r}$ with phases (XYXYYXYX) $)_{n}$ was applied to favor polarization transfer via the homonuclear ${ }^{13} \mathrm{C}-{ }^{13} \mathrm{C}$ dipolar couplings. For coherence transfer, the pathway selection and ringdown elimination the phase cycle for $\varphi_{2}, \varphi_{3}$, and $\varphi_{\text {ref }}$ listed in Table 1 were used. ${ }^{34}$

$\mathrm{A}^{13} \mathrm{C}_{1}$ of $\sim 30 \mathrm{~s}$ was measured with a CP MAS inversion recovery experiment. A rotor-synchronized dante pulse sequence was used for selective inversion of signals in the 1D ${ }^{1} \mathrm{H}$-driven spin-diffusion experiments, while for the $1 \mathrm{D}$ rotational resonance experiment asynchronous dante excitation was used. ${ }^{36}$

Spin diffusion will be quenched when the dipolar coupling is averaged on the time scale of the NMR experiment by rapid molecular motions. Wide line ${ }^{1} \mathrm{H}$ NMR spectra of commercial SAN28, SMA28, and their 50/50 (w/w) blend show very broad resonances with a line width of $\sim 42 \mathrm{kHz}$ (data not shown). Thus, it is clear that the materials are rigid and that the nuclei are strongly coupled through dipolar interactions.

\section{Results and Discussion}

Figure 5 shows the ${ }^{13} \mathrm{C} C P$ MAS NMR spectrum of a $50 / 50(\mathrm{w} / \mathrm{w}$ ) blend of the labeled SMA and SAN copolymers. The signals are inhomogeneously broadened, which shows that the polymer blend is structurally heterogeneous on the scale of the NMR. The response from the SAN nitrile labels has a shift $\delta=121 \mathrm{ppm}$, while the SMA methylene and carbonyl label s resonate with $\delta=40$ and $172 \mathrm{ppm}$, respectively. The chemical shifts of the labels are the same as those for the copolymers in solution (Figure 2). $\mathrm{Sp}$ or $\mathrm{sp}^{2}$-type carbons have large chemical shift anisotropies (CSA). Hence, spinning sidebands from the nitrile and carbonyl groups are observed at integral multiples of the sample spinning speed, $\omega_{\mathrm{r}} / 2 \pi=10 \mathrm{kHz}$, corresponding with 100 ppm.

Figure 6a shows the 2D ${ }^{13} \mathrm{C}$ CP MAS NMR dipolar correlation spectrum of an anneal ed 50/50 (w/w) blend of $\left[{ }^{13} \mathrm{CH}_{2},{ }^{13} \mathrm{CO}\right] S M A 27$ and $\left[{ }^{13} \mathrm{CN}\right] \mathrm{SAN} 27$ recorded with the RFDR sequence using $\omega_{\mathrm{r}} / 2 \pi=10 \mathrm{kHz}$. The spectrum was obtained with a short mixing period $\tau_{\mathrm{m}}=800$ $\mu \mathrm{s}$. For short $\tau_{\mathrm{m}}$ or weak dipolar interactions, spin exchange is effectively prohibited and the 2D spectrum only contains sideband lines parallel to the diagonal at multiples of $\omega_{r} / 2 \pi$, as indicated by the dotted lines. The same experiment was performed with $\tau_{\mathrm{m}}=11.2 \mathrm{~ms}$. In that case, intramolecular polarization transfer between the SMA carbonyl $(\delta=172 \mathrm{ppm})$ and the SMA meth- 

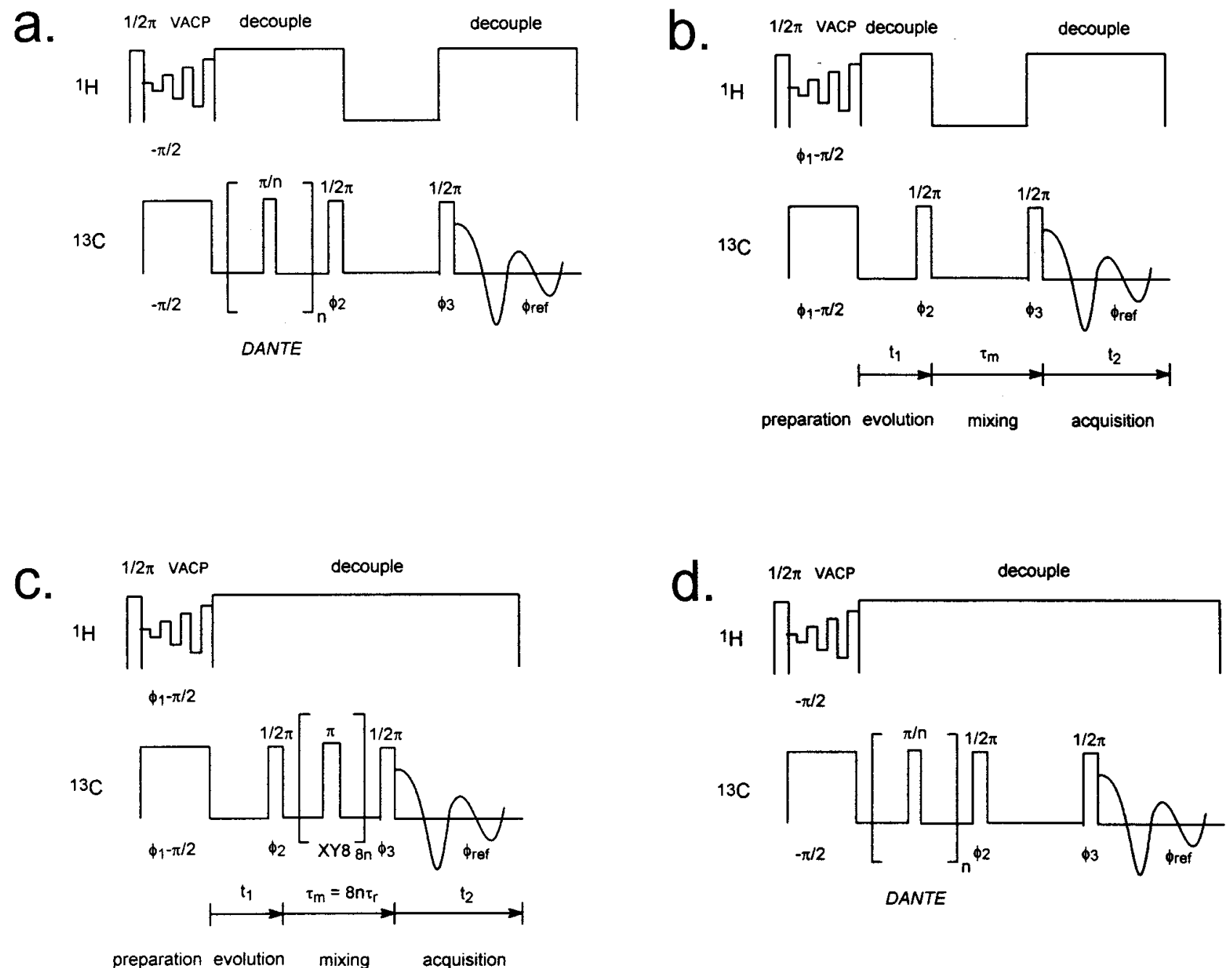

Figure 4. Schematic representation of the (a) $1 \mathrm{D}{ }^{1} \mathrm{H}$-driven ${ }^{13} \mathrm{C}$ spin diffusion, (b) $2 \mathrm{D}{ }^{1} \mathrm{H}$-driven ${ }^{13} \mathrm{C}$ spin diffusion, (c) RFDR, and (d) 1D rotational resonance. Relevant nutation angles are depicted on top of the corresponding pulses, whilerf phases are indicated beneath the pulses.

Table 1. Eight-Step Phase Cycle Used for the Pulse Sequences in Figure $\mathbf{4 b}, \mathbf{c}^{\mathbf{a}}$

\begin{tabular}{|c|c|c|c|c|c|c|c|c|}
\hline & 1 & 2 & 3 & 4 & 5 & 6 & 7 & 8 \\
\hline$\varphi_{2}$ & 0 & 0 & 0 & 0 & $\pi$ & $\pi$ & $\pi$ & $\pi$ \\
\hline $\begin{array}{l}\varphi_{2} \\
\varphi_{3}\end{array}$ & 0 & $\pi / 2$ & $\pi$ & $3 \pi / 2$ & 0 & $\pi / 2$ & $\pi$ & $3 \pi / 2$ \\
\hline$\varphi_{\text {ref }}$ & 0 & $\pi / 2$ & $\pi$ & $3 \pi / 2$ & $\pi$ & $3 \pi / 2$ & 0 & $\pi / 2$ \\
\hline
\end{tabular}

ylene ( $\delta=40$ ppm) resonances give rise to cross-peaks between the two MAS patterns, as indicated by thethick arrows (Figure 6b). This shows that intramolecular spin diffusion between the SMA carbonyl and methylene occurs on a time scale of several milliseconds. This is due to the short ${ }^{13} \mathrm{CH}_{2}-{ }^{13} \mathrm{CO}$ distance of $\sim 3 \AA$, yiel ding a dipolar interaction of $\omega_{\mathrm{D}} / 2 \pi \sim 300 \mathrm{~Hz}$.

${ }^{13} \mathrm{C}$ spin diffusion can be mediated by the dipolar field generated by the protons. In the spectra obtained by ${ }^{1} \mathrm{H}$-driven ${ }^{13} \mathrm{C}$ spin-diffusion experiments using $\tau_{\mathrm{m}}=2$ $\mathrm{s}$ (Figure $6 \mathrm{c}$ ), the cross-peaks indicated by the thin arrows occur at $\delta_{1}, \delta_{2}=[121,172]$ and $[172,121]$ and $\delta_{1}$, $\delta_{2}=[121,40]$ and $[40,121]$ ([ppm,ppm]). They reveal intermolecular polarization transfer by spin diffusion between the SAN nitriles and the SMA carbonyls and methylenes, respectively.

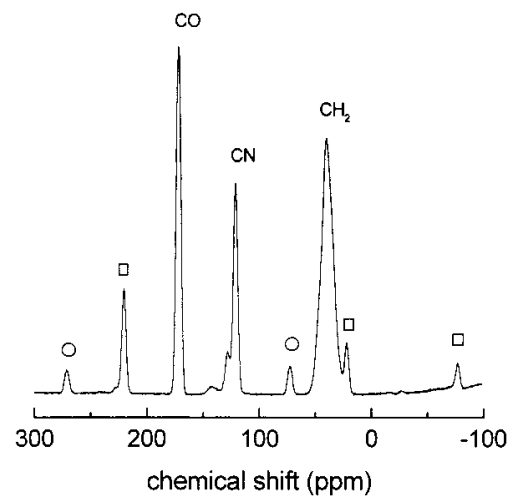

Figure 5. ${ }^{13} \mathrm{C} C P$ MAS NMR spectrum of the annealed $50 / 50$ $(\mathrm{w} / \mathrm{w})$ blend of $\left[{ }^{13} \mathrm{CN}\right] \mathrm{SAN} 27$ and $\left[{ }^{13} \mathrm{CH}_{2},{ }^{13} \mathrm{CO}\right] \mathrm{SMA} 27$, recorded with $\omega_{\mathrm{r}} / 2 \pi=10 \mathrm{kHz}$. Nitrile spinning sidebands are marked with $\square$, carbonyl spinning sidebands are marked with $\bigcirc$.

The fast intramolecular spin diffusion in $\left[{ }^{13} \mathrm{CH}_{2},{ }^{13} \mathrm{CO}\right]-$ SMA27 can also be detected using straightforward ${ }^{13} \mathrm{C}$ rotor-driven spin diffusion at $n=1$ rotational resonance with $\omega_{\mathrm{r}} / 2 \pi=13313 \mathrm{~Hz}$. After the cross-polarization, the methylene response is selectively inverted with an asynchronous dante sequence. The difference magnetization is probed by measuring the peak areas. For increasing $\tau_{\mathrm{m}}$, the difference magnetization decreases due to polarization exchange between the SMA meth- 
a.

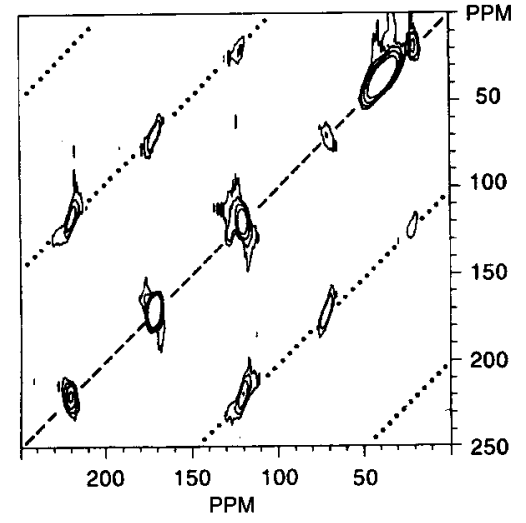

b.

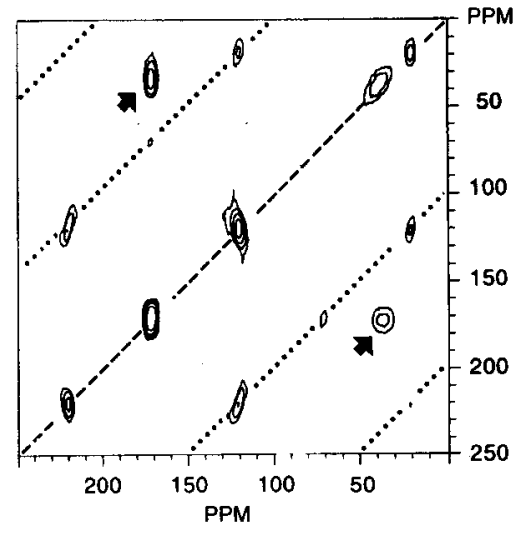

C.

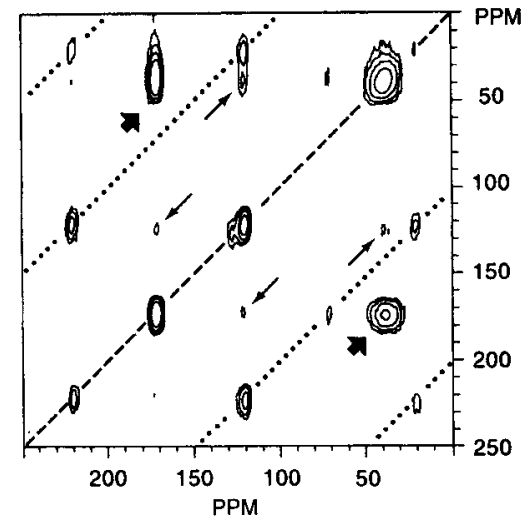

Figure 6. $2 \mathrm{D}{ }^{13} \mathrm{C} C P$ MAS NMR dipolar correlation spectra of the annealed 50/50 (w/w) blend of $\left[{ }^{13} \mathrm{CN}\right] \mathrm{SAN} 27$ and $\left.{ }^{13} \mathrm{CH}_{2},{ }^{13} \mathrm{CO}\right] S M A 27$. Spectra $a$ and $b$ were collected with the RFDR pulse sequence of Figure $3 \mathrm{c}$ with $\tau_{\mathrm{m}}=80 \mathrm{~ms}(\mathrm{a})$ and $112 \mathrm{~ms}(\mathrm{~b})$. The data in spectra c were acquired with the ${ }^{1} \mathrm{H}$ driven ${ }^{13} \mathrm{C}$ spin-diffusion sequence of Figure $4 \mathrm{~b}$ with $\tau_{\mathrm{m}}=2 \mathrm{~s}$. Thick and thin arrows indicate the most pronounced correlations from intra- and intermolecular spin diffusion, respectively. Dashed and dotted lines indicate the diagonal and its spinning sidebands. Sixty-four slices of eight scans were recorded for each spectrum. An exponential multiplication of $50 \mathrm{~Hz}$ was used in $\mathrm{t}_{2}$ and a sine-squared apodization shifted by $\pi / 2$ was used in $t_{1}$. Spectra are plotted using the same set of contour levels and the data are zero filled in $t_{1}$ to 1024 points prior to Fourier transformation.

ylenes and the adjacent carbonyls (Figure 7). Since a MA is al ways flanked by two styrene units, the carbonyl labels are al ways either two single bonds or three single bonds away. The efficient intramolecular spin diffusion can be attributed to short intramolecular distances of 2.5-3.5 $\AA$ between the SMA carbonyl and SMA methylene ${ }^{13} \mathrm{C}$ atoms. In contrast, when the experiment is performed at the $n=1$ rotational resonance condition for the SMA methylene and the SAN nitrile $\omega_{\mathrm{r}} / 2 \pi=$ $8211 \mathrm{~Hz}$, the peak areas of the SMA methylene and SAN

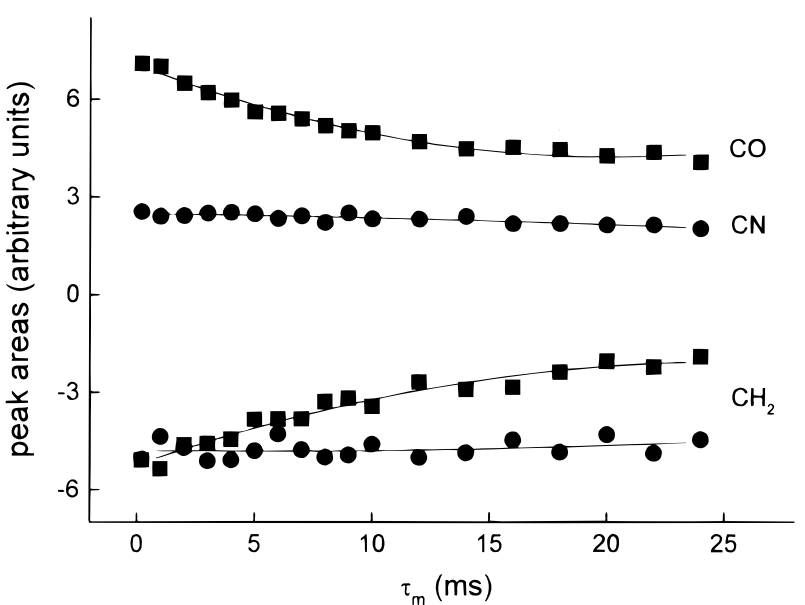

Figure 7. Areas of the center bands of the SMA carbonyl, the SAN nitrile, and the SMA methylene MAS patterns versus $\tau_{\mathrm{m}}$ in blends. Filled squares represent the data recorded with $\omega_{\mathrm{r}} / 2 \pi=13313 \mathrm{~Hz}$ at the $\mathrm{n}=1$ rotational resonance condition for the label pairs in SMA. The circles represent the data recorded with $\omega_{\mathrm{r}} / 2 \pi=8211 \mathrm{~Hz}$ as the rotational resonance condition for the SAN ${ }^{13} \mathrm{CN}$ and the SMA ${ }^{13} \mathrm{CH}_{2}$ response. The lines are guides to the eyes.

nitrile responses remain essentially constant during mixing times of up to $24 \mathrm{~ms}$. This provides strong evidence that the intermolecular distance between the labeled sites in SMA SAN blends is more than $3 \AA$.

Miscibility of SMA and SAN. High rotor speeds attenuate the ${ }^{1} \mathrm{H}-{ }^{13} \mathrm{C}$ heteronuclear dipolar interactions. Therefore, another set of spin-exchange experiments was conducted at a lower $\omega_{\mathrm{r}} / 2 \pi=$ of $3500 \mathrm{~Hz}$. This value for $\omega_{r}$ is convenient since there is little spectral overlap between the centerband and sideband responses from the various labeled sites. The data collected at the lower spinning speed are well in line with the high-speed measurements. Figure 8 shows 2D correlation spectra of an anneal ed 50/50 (w/w) blend of the two labeled SMA and SAN copolymers. For a mixing time of $10 \mathrm{~ms}$ (Figure 8a), only correlations between center bands and their spinning sidebands are observed. When $\tau_{\mathrm{m}}$ is increased to $50 \mathrm{~ms}$ (Figure 8b), strong intramolecular correlations between the SMA carbonyl and methylene responses can be detected. Finally, for $\tau_{\text {inter }}=2 \mathrm{~s}$, intermolecular cross-peaks between the SAN nitrile and the carbonyl and methylene responses from SMA emerge (Figure 8c). The ${ }^{13} \mathrm{CN}$ to ${ }^{13} \mathrm{CO}$ and ${ }^{13} \mathrm{CN}$ to ${ }^{13} \mathrm{CH}_{2}$ correlations appear at approximately the same rate, since magnetization transferred from the SAN nitrile to any one of the SMA labels can be rapidly passed on to the other SMA label through the stronger intramolecular dipolar couplings.

The cross-peak intensity is proportional to the spin diffusion rate, i.e., $\mathrm{P}(\mathrm{t}) \propto \omega_{\mathrm{D}}^{2} \tau_{\mathrm{m}}$, with $\omega_{\mathrm{D}} \propto \mathrm{r}^{-3}$. Here we neglect the effect of the line shape function $g_{0} j k$, since the $r^{-6}$ dependence will be a predominant factor determining the minimum mixing time necessary to allow the observation of a cross-peak. The shortest possible $r_{\text {intra }}=2.5 \AA$. However, the intensities of the intramolecular cross-peaks relative to the intensity of the diagonal are saturated al ready for a mixing time $\tau_{\text {intra }}$ $=50 \mathrm{~ms}$. This should imply that the majority of the possible $r_{\text {intra }} \gtrsim 2.5 \AA$ are sampled within this period. Weak intermolecular correlations appear after a minimum mixing time $\tau_{\text {inter }}$, approximately 40 times as Iong as the $\tau_{\text {intra }}$ for the saturation of the intramolecular correlations over a distance $r_{\text {intra }} \gtrsim 2.5 \AA$. Since $P\left(\tau_{\text {inter }}\right)$ 

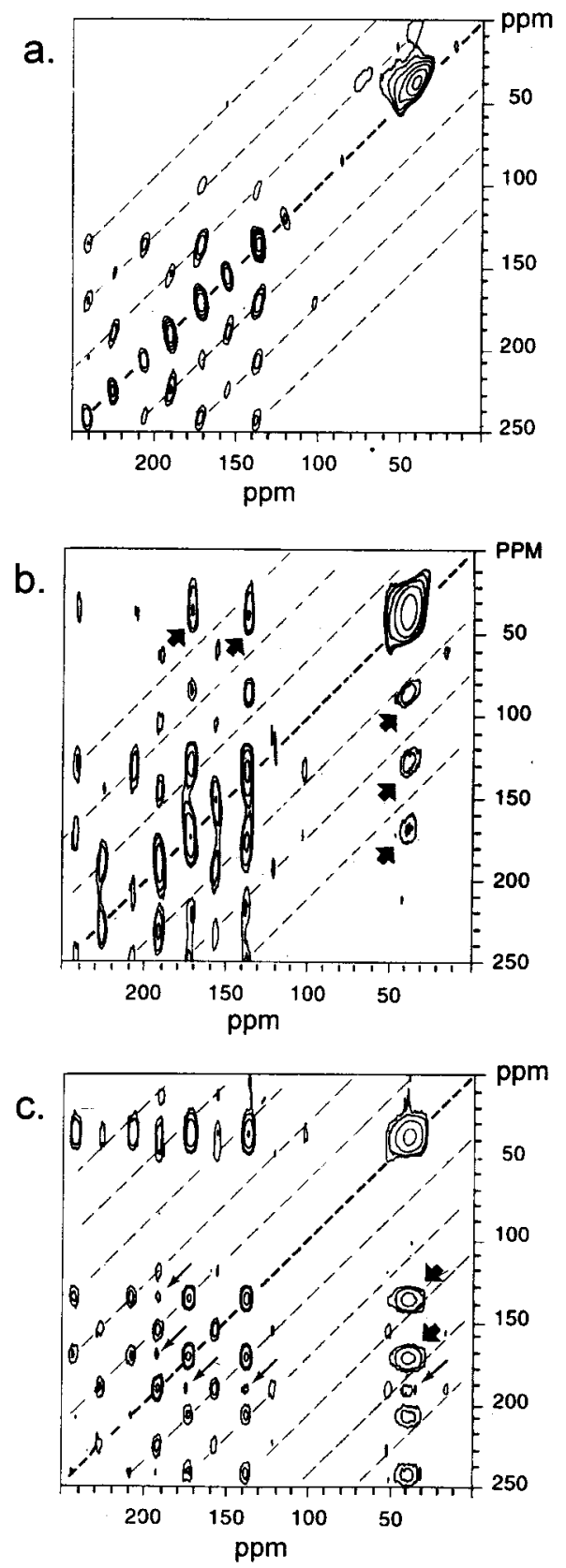

Figure 8. $2 \mathrm{D}{ }^{13} \mathrm{C} C P$ MAS NMR dipolar correlation spectra of the annealed $50 / 50(\mathrm{w} / \mathrm{w})$ blend of $\left[{ }^{13} \mathrm{CN}\right] \mathrm{SAN} 27$ and $\left.{ }^{13} \mathrm{CH}_{2},{ }^{13} \mathrm{CO}\right] \mathrm{SMA} 27$ obtained using ${ }^{1} \mathrm{H}$-driven ${ }^{13} \mathrm{C}$ spin diffusion with $\tau_{\mathrm{m}}=10 \mathrm{~ms}(\mathrm{a}), \tau_{\mathrm{m}}=50 \mathrm{~ms}$ (b), and $\tau_{\mathrm{m}}=2 \mathrm{~s}$ (c). Thick and thin arrows indicate correlations from intra- and intermolecular spin diffusion, respectively. Dashed lines represent the diagonal and its spinning sidebands. An exponentral multiplication of $50 \mathrm{~Hz}$ was used in $t_{2}$ and a sine-squared apodization shifted by $\pi / 2$ was used in $t_{1}$. The spectra consist of 32 slices of 64 scans each and are plotted using the same set of levels and the data are zero filled to 1024 points prior to Fourier transformation.

$<\mathrm{P}\left(\tau_{\text {intra }}\right)$, it follows that $\mathrm{r}_{\text {inter }} / \mathrm{r}_{\text {intra }}>\left(\tau_{\text {inter }} / \tau_{\text {intra }}\right)^{1 / 6}$, yielding $r_{\text {inter }}>2 r_{\text {intra. }}$.

The miscibility in blends of polyacrylonitrile and poly(ethene-co-maleic anhydride) has been attributed to attractive nonbonding interactions between mutually ordered anhydride and nitrile electric dipoles. ${ }^{11}$ From molecular modeling data it can be inferred that such interactions lead to a tight packing with a characteristic ${ }^{13} \mathrm{CO}$ to $^{13} \mathrm{CN}$ distance of $\sim 4 \AA .11$ We note that for the minimum $r_{\text {intra }}=2.5 \AA$ we find $r_{\text {inter }}>5 \AA$, which is

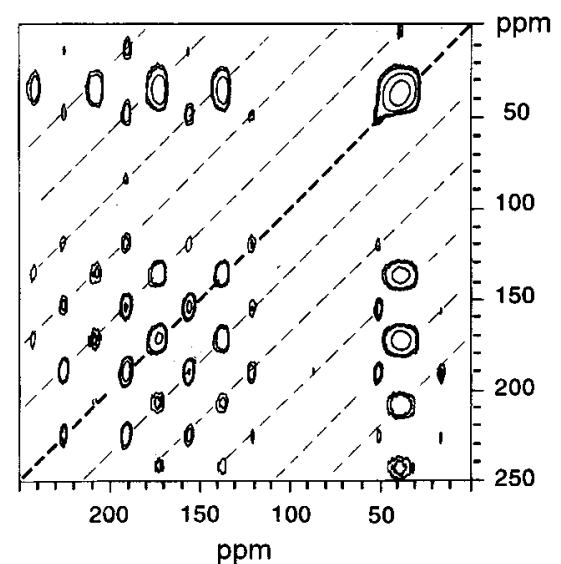

Figure 9. $2 \mathrm{D}{ }^{13} \mathrm{C} C \mathrm{CP}$ MAS NMR dipolar correlation spectrum of the annealed 50/50 (w/w) semi-IPN prepared from a 50/50 (w/w) $\left[{ }^{13} \mathrm{CH}_{2},{ }^{13} \mathrm{CO}\right] \mathrm{SMA} 27\left[{ }^{13} \mathrm{CN}\right]$ SAN27 blend cross-linked with 0.5 equiv of 4,4'-methylenedianiline per SMA anhydride group. The data were collected with the ${ }^{1} \mathrm{H}$-driven ${ }^{13} \mathrm{C}$ spindiffusion sequence of Figure $3 \mathrm{~b}$ with $\tau_{\mathrm{m}}=2 \mathrm{~s}$. Dashed lines indicate the diagonal and its spinning sidebands. Sixty-four slices of 64 scans were recorded. An exponential multiplication of $50 \mathrm{~Hz}$ was used in $\mathrm{t}_{2}$ and a sine-squared apodization shifted by $\pi / 2$ was used in $t_{1}$. The data set was zero filled to 1024 points prior to Fourier transformation.

difficult to reconcile with the $4 \AA$ from the modeling studies. For an average intramolecular distance be tween the labeled sites in SMA of $r_{\text {intra }} \sim 3 \AA$, a minimum intermolecular distance between the labeled sites in the $50 / 50(\mathrm{w} / \mathrm{w})$ blend of $\left[{ }^{13} \mathrm{CN}\right] \mathrm{SAN} 27$ and $\left[{ }^{13} \mathrm{CO},{ }^{13} \mathrm{CH}_{2}\right]-$ $\mathrm{SMA} 27$ of $r_{\text {inter }}=6 \AA$ can be estimated. Hence, there is no evidence for a mutual ordering of the carbonyl and nitrile moieties as a result of a specific exothermic interactions between the electric dipole moments of both functionalities. This is well in line with the observation of considerable inhomogeneous broadening of the label resonances in the spectra, reflecting the structural heterogeneity of their chemical environments.

Phase Separation in SMA/SAN Mixtures. The cross-peaks between the SAN nitrile and the SMA methylene and carbonyl responses in the $2 \mathrm{D}$ spectrum from the annealed 50/50 (w/w) blend recorded with $\tau_{\mathrm{m}}$ $=2 \mathrm{~s}$ (Figure $8 \mathrm{c}$ ) prove that the two polymers are intimately mixed at the molecular level. In contrast, the SMA and SAN components should be phase separated at a microscopic level in the Semi-IPN that was prepared using 0.5 equiv of 4,4'-methylenedianiline cross-linker per SMA anhydride functionality, since there are no intermolecular cross-peaks for the long $\tau_{\mathrm{m}}$ $=2 \mathrm{~s}$ (Figure 9). These results are in good agreement with the DSC experiments (Figure 2). With the 1D sequence of Figure $3 a^{1} \mathrm{H}$-driven ${ }^{13} \mathrm{C}$ spin diffusion can be used to examine morphology development in polymeric materials at the microscopic level. Figure 10 shows the 1D ${ }^{13} \mathrm{C} C P$ MAS NMR spectra of a series of the label ed semi-IPN's obtained by cross-linking SMA/ SAN blends. First, data were recorded of the anneal ed $50 / 50$ (w/w) blend with a rotor-synchronized DANTE sequence to invert the SAN nitrile responses (Figure 10a). Clearly the $\tau_{\mathrm{m}}=1 \mathrm{~ms}$ is not sufficiently long to allow for reequilibration of the polarization by intermolecular spin-diffusion processes. For $\tau_{\mathrm{m}}=20 \mathrm{~s}$ (Figure 10b), the SAN nitrile responses have acquired positive intensity, which is mainly due to polarization transfer from the SMA and SAN labels and partly due to longitudinal relaxation, since $\mathrm{T}_{1} \sim 30 \mathrm{~s}$ for this compound. 


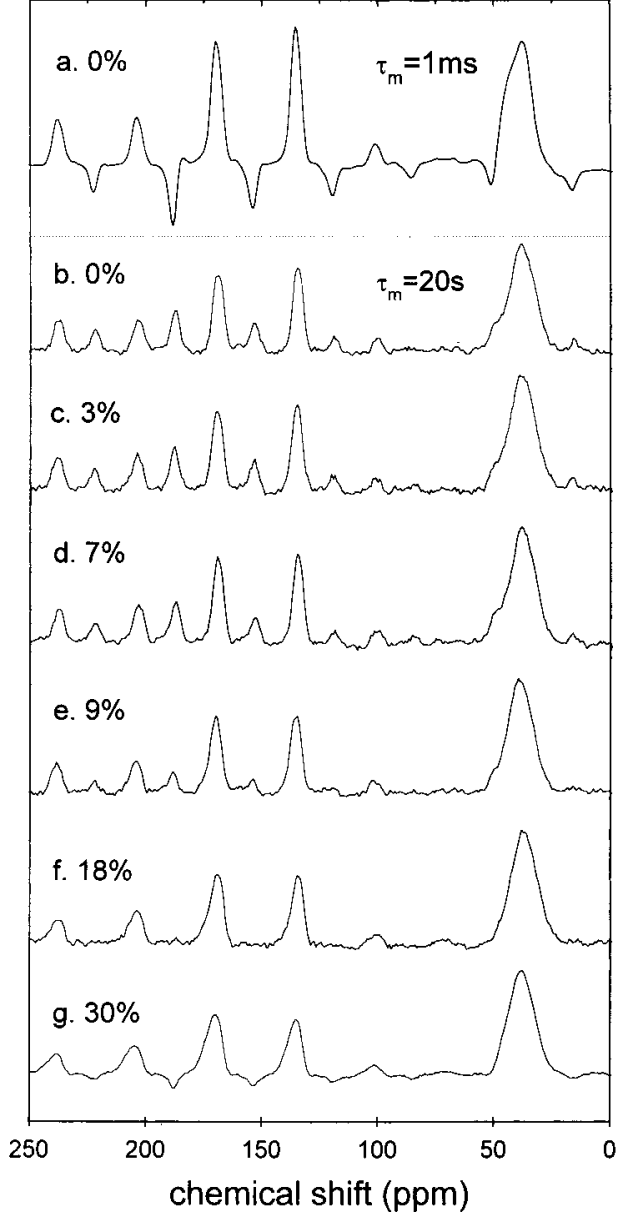

Figure 10. $1 \mathrm{D}{ }^{13} \mathrm{C}$ CP $\mathrm{MAS}{ }^{1 \mathrm{H}}$-driven ${ }^{13} \mathrm{C}$ spin-diffusion experiments on an annealed 50/50 (w/w) blend $(a, b)$ and semiIPNs (c-f) of $\left.{ }^{[3} \mathrm{CN}\right]$ SAN 27 and $\left[{ }^{13} \mathrm{CH}_{2},{ }^{13} \mathrm{C}=0\right]$ SMA27 using the sequence of Figure $3 \mathrm{a}$ with $\tau_{\mathrm{m}}=1 \mathrm{~ms}(\mathrm{a})$ and $\tau_{\mathrm{m}}=20 \mathrm{~s}$ $(\mathrm{b}-\mathrm{g})$. The semi-I PNs were made with 4,41-methylenedianiline corresponding to 3\% (c), 7\% (d), 9\% (e), 18\% (f), and 30\% (g) dianiline functionality relative to the $\mathrm{CO}$ functionalities in SMA.

Phase separation is more pronounced as the crosslink density is increased. This is demonstrated with the 1D spin-diffusion spectra of the semi-IPNs in which $18 \%$ and $30 \%$ of the monomeric units in SMA may be part of a cross-link (Figures 10 and $g$, respectively). In the blend containing SMA with at most $18 \%$ cross-links, the SAN nitrile polarization has relaxed to zero intensity after $\tau_{\mathrm{m}}=20 \mathrm{~s}$. For the material prepared with an equival ent of diamine to react with all SMA anhydride groups, the nitrile response still has negative intensity. In both materials the recovery is probably mainly due to $\mathrm{T}_{1}$ relaxation. The intermolecular spin diffusion proceeds very slowly, and the materials are strongly phase-separated. The spectra in Figure 10 belong to semi-IPNs that were prepared with a smaller amount of the difunctional 4,4'-methylene dianiline sufficient to cross-link 3\% (Figure 10c) or 7\% (Figure 10d) of the monomeric units in SMA. The NMR responses are similar to the data for the pure blend, which provides convincing evidence that polarization transfer from the SMA ${ }^{13} \mathrm{C}$ nuclei to the SAN nitrile proceeds easily during $\tau_{\mathrm{m}}=20 \mathrm{~s}$. However, if the semi-I PN is prepared with approximately $\sim 9 \%$ equivalent of cross-linker, relative to the amount of anhydride moieties in SMA, which is sufficient to cross-link 0.17 of the SMA monomer, the nitrile responses remain inverted after 20 s of spin diffusion (Figure 10e). Thus, the 1D data confirm that the system is, to some extent, phase-separated, since the average distance between the nuclei of SAN and SMA is larger than for the miscible blend or for moderately cross-linked semi-IPNs. This correlates again with the DSC data, since the $9 \%$ cross-linked material exhibits a broad glass-rubber transition (cf. Figure 3g).

\section{Conclusions}

For materials with strongly overlapping ${ }^{1} \mathrm{H}$ responses and similar $\mathrm{T}_{1}$ 's, such as the glassy SAN and SMA thermoplastics, site-directed isotopic enrichment all ows the use of solid-state ${ }^{13} \mathrm{C}$ spin-diffusion NMR techniques to characterize miscibility and the extent of phase separation. Using 2D $1 \mathrm{H}$-driven-spin diffusion techniques on blends of $\left[{ }^{13} \mathrm{CH}_{2},{ }^{13} \mathrm{CO}\right] \mathrm{SMA} 27$ and $\left[{ }^{13} \mathrm{CN}\right]-$ SAN27, it was demonstrated that SMA and SAN are miscible on the molecular level. A specific orientation of the nitrile moieties in SAN with respect to the carbonyl groups in SMA is unlikely. Most probably the miscibility of SAN and SMA copolymers is related to a relief of intramolecular repulsion upon mixing, as opposed to a highly specific exothermic binary interaction involving a preferential mutual orientation of the MA and $\mathrm{AN}$ moieties. In addition, ${ }^{1} \mathrm{H}$-driven ${ }^{13} \mathrm{C}$ spindiffusi on techniques were used to investigate demixing in SMA/SAN mixtures as a result of cross-linking with diamine. It was shown that the degree of phase separation in mixtures of $\left[{ }^{13} \mathrm{CH}_{2},{ }^{13} \mathrm{CO}\right] \mathrm{SMA} 27$ and $\left[{ }^{13} \mathrm{CN}\right]-$ SAN 27 increases with the degree of cross-linking.

Acknowledgment. The support of F. Lefeber, C. Erkelens, E. Verdurmen, and G. Vonk during various stages of this work is gratefully acknowledged. This work is financed in part by the Netherlands Foundation for Technical Research STW (contract 341-3185).

\section{References and Notes}

(1) S. Kranse, J . Macromol, Sci-Reviews. Macromol. Chem. 1972, C7, 251.

(2) Hall, W. J .; Kruse, R. L.; Mendelson, R. A.; Trementozzi, Q. A. Am. Chem. Soc., Div. Org. Chem. Plast. Prepr. 1982, 47, 298

(3) Gan, P. P.; Paul, D. R J . Appl. Polym. Sci. 1994, 54, 317.

(4) Kato, T.; Kobayashi, N.; Takahashi, A. Kobunshi Ronbonshu $1983,40,661$.

(5) Aoki, Y. Polym. J . 1984, 16, 431.

(6) Kressler, J .; Kammer, H. W.; Schmidt-Naake, G.; Herzog, K. Polymer 1988, 29, 686.

(7) Cowie, J . M. G.; Lath, D. Macromol . Chem., Macromol. Symp. 1988, 16, 103

(8) Aoki, Y. Macromolecules 1988, 21, 1277

(9) Kim, J. H.; Barlow, J . W.; Paul, D. R. J . Polym. Sci. Part B: Polym. Phys. 1989, 27, 223.

(10) Paul, D. R.; Barlow, J. W. Polymer 1984, 25, 487.

(11) Persec, S.; Gray, J . J . Macromol. Sci. PureAppl. Chem. 1995, A32, 1563

(12) Fay, J . J .; Murphy, C. J .; Thomas, D. A.; Sperling, L. H. Polym. Eng. Sci. 1991, 31, 1731.

(13) De Graaf, L. A. Morphology Control in Semi-Interpenetrating Polymer Networks-Two Approaches. Thesis, Universiteit Twente, 1994.

(14) Sperling, L. Interpenetrating Networks and Related Materials, Plenum Press: New York, 1981.

(15) Duprez, F.; Goethals, E. J . Macromol. Chem. Phys. 1995, 196, 903.

(16) Patri, M.; Samui, A.B; Deb, P. C. J . Appl. Polym. Sci. 1993, 863, 1709.

(17) Cheung, T. T. P. Phys. Rev. B 1981, 23, 1404.

(18) Schmidt-Rohr, K.; Clauss, J .; Blumich, B.; Spiess, H. W. Magn. Reson. Chem. 1990, 28, s3 
(19) White, J . L.; Mirau, P. Macromolecules 1993, 26, 3049.

(20) Cho, G. Can. J . Chem. 1994, 72, 2255.

(21) Kimura, T.; Neki, K.; Tamura, N.; Horii, F.; Nakagawa, M.; Odani, H. Polymer 1992, 33, 493

(22) Spiegel, S.; Landfester, K.; Lieser, G.; Boeffel, C.; Spiess, H. W.; Eidam, N. Macrmol. Chem. Phys. 1995, 196, 985

(23) Kulik, A. S.; Haverkamp, J. Polymer 1995, 36, 427.

(24) Bloembergen, N. Physica 1949, XV, 386.

(25) Abragam, A. ThePrinciples of Nuclear Magnetization; Oxford University Press: London, 1961.

(26) Levitt, M. H.; J . Chem. Phys. 1990, 10, 6347.

(27) Raleigh, D. P.; Levitt, M. H.; Griffin, R. G. Chem. Phys. Lett. 1988, 146, 71.

(28) Raleigh, D. P.; Creuzet, F.; DasGupta, S. K.; Levitt, M. H.; Griffin, R. G. J . Am. Chem. Soc. 1989, 111, 4502.

(29) Pavlovskaya, G. Macromolecules 1993, 26, 6310.

(30) Bennett, A. E.; Ok, J. H.; Griffin, R. G.; Vega, S. J . Chem. Phys. 1992, 96, 8624

(31) Boender, G.J .; Raap, J .; Prytulla, S.; Oschkinat, H.; De Groot, H. J. M. Chem. Phys. Lett. 1995, 237, 502.

(32) Robyr, P.; Tomaselli, M.; Straka, J .; Grobpisano, C.; Suter, U. W.; Meier, B. H.; Ernst, R. R. Mol. Phys. 1995, 84, 995.

(33) Olejniczak, E. T.; Vega, S.; Griffin, R. G.; J . Chem. Phys. 1984, $81,4804$.

(34) Wang, P.; J ones, A. A.; Inglefield, P. T.; White, D. M.; Bendler, J. T. New Polym. Mater. 1990, 2, 221.

(35) Henrichs, P. M.: Linder, M. J. Magn. Reson. 1984, 58, 458.

(36) Caravatti, P.; Deli, J . A.; Bodenhausen, G.; Ernst, R. R. J . Am. Chem. Soc. 1982, 104, 5506.

(37) Szeverenyi, N. M.; Sullivan, M. J .; Maciel, G. E. J . Magn. Reson. 1982, 47, 462.

(38) Linder, M.; Henrichs, P. M., Hewitt, J . M.; Massa, D. J . J . Chem. Phys. 1985, 82, 1585.
(39) Kolbert, A. C.; Caldarelli, S.; Thier, K. F.; Sariciftci, N. S.; Cao, Y.; Heeger, A. J. Phys. Rev. B 1995, 51, 1541

(40) Edzes, H. T.; Bernards, J . P. C. J . Am. Chem. Soc. 1984, 106, 1515.

(41) Bronniman, C. E.; Szeverenyi, N. M.; Maciel, G. E. J . Chem. Phys. 1983, 79, 3694.

(42) Bestmann, H.J .; Kisielowski, L.; Distler, W. Angew. Chem. 1976, 88, 297.

(43) Heinen, W.; Rosenmöller, C. B.; Wenzel, H. J . M.; De Groot, H.J . M.; Lugtenburg, J .; Van Duin, M. Macromol ecules 1996, 29, 1151.

(44) Heinen, W. Grafting of Polyol efins and Miscibility in Copolymer Mixtures-Studies of Polymers on the Atomic Level with Site-Specific I sotope Enrichment and NMR. Thesis, Leiden University, 1996.

(45) Wiersum, U. E. Recl. Trav. Chim. Pays-Bas 1982, 101, 317.

(46) Van den Berg, E. M. M.; Richardson, E. E.; Lugtenburg, J .; J enneskens, L. W. Synth. Commun. 1987, 17, 1189.

(47) Venema, A.; Nibbering, N. M. M.; De Boer, T. J . Org. Mass Spectrom. 1970, 3, 1589.

(48) O'Driscoll, K. F.; Burczyk, A. F. Polym. React. Engin. 1992, $1,111$.

(49) Klumperman, L. Free Radical Copolymerization of Styrene and Maleic Anhydride. Kinetic Studies at Low and Interme diate Conversion. Thesis, Technical University Eindhoven, 1994.

(50) Barron, P. F.; Hill, D. J . T.; O'Donnell, J . H.; O'Sullivan, P. W. Macromolecules 1984, 17, 1967.

(51) Brown, P. G.; Fujimori, K. Macromol. Rapid Commun. 1994 15,61 .

MA980436N 